\title{
Remembranzas del Congreso de los Postgrados de Medicina en su Vigésimoquinto Aniversario*
}

\author{
Remembrances of the Medical Postgraduate Programs Meetings in their twenty-fifth anniversary \\ Martha Matamoros Aguilar \\ Pediatra Intensivista. \\ Coordinación de Investigación, Postgrados de Medicina 2004-2008; Comité Apoyo Coordinación General, \\ Postgrados de Medicina 2002-2004; Coordinación Postgrado de Pediatría, Postgrados de Medicina 1992-2002; \\ Facultad de Ciencias Médicas UNAH, Tegucigalpa.
}

\section{INTRODUCCIÓN}

En ocasión de la celebración del del XXV Congreso de los Postgrados de Medicina y Encuentro de Egresados y $8^{\text {vo }}$ Congreso Multidisciplinario de los Postgrados de Medicina Clínica, Salud Pública, Enfermería y Epidemiología, celebrado en Tegucigalpa, del 9 al 11 de septiembre de 2019, es para mí un honor haber sido invitada a la ceremonia de clausura y poder compartir mis remembranzas de los orígenes y consolidación de estos eventos científicos.

Es grato para mi volver a estos espacios académicos que traen a mi mente, bellos recuerdos, de sueños y metas alcanzadas que significaron para mí y mis compañeros de la Coordinación de los Postgrados de Medicina grandes desafíos, muchas horas de trabajo, alegrías por los éxitos, tristeza por los fracasos y preocupaciones por la incertidumbre. Sin embargo, todas estas emociones juntas forman un tesoro que no se compra con ninguna tarjeta de crédito y que al ser invitada este día para compartir estas remembranzas en el marco de la celebración del vigesimoquinto aniversario apreciamos que si valió la pena y especialmente cuando vemos que los Congresos de los Postgrados Médicos se han mantenido a lo largo del tiempo y que además se sumaron los postgrados de salud pública, epidemiología y enfermería.

\section{ORIGEN DE LOS CONGRESOS}

Siendo coordinadora del Postgrado de Pediatría, me involucré apasionada y responsablemente con el desarrollo de éste postgrado. Identificamos las fortalezas y debilidades que existían. Iniciamos con el apoyo del Jefe del Departamento de Pediatría del Hospital Escuela, Dr. Francisco Cleaves, y del coordinador académico del Postgrado de Pediatría IHSS, Dr.

*El contenido de este artículo está fundamentado en la ponencia sobre las Remembranzas del Congreso de los Postgrados de Medicina presentada en la Ceremonia de Clausura del XXV Congreso de los Postgrados de Medicina y Encuentro de Egresados y 8vo Congreso Multidisciplinario de los Postgrados de Medicina Clínica, Salud Pública, Enfermería y Epidemiología, Tegucigalpa, Setiembre 9-11, 2019.

Recibido: 12-9-2019 Aceptado para publicación 14-11-2020

Dirección para correspondencia: Dra. Martha Matamoros

Correo electrónico: mmmatamoros@hotmail.com

Conflictos de interés. La autora declara no poseer conflictos de interés en relación al presente artículo.

DOI: https://doi.org/10.5377/rmh.v87i2.11920
Emilso Zelaya, una reingeniería del proceso de formación de los futuros pediatras. Además de la implementación del programa académico por niveles de complejidad, realizamos la Primera Jornada Científica del Postgrado de Pediatría, a la cual asistimos todos los médicos del Departamento, los residentes de todos los niveles y estudiantes de grado. Era la primera vez que una Jornada sobre trabajos originales de investigación se realizaba en la vida de este Postgrado. La enseñanza que nos dejó esta Jornada fue muy valiosa y concluimos lo siguiente: 1) Existe una riqueza en casuística; 2) El proceso puede mejorar y debe ser revisado; 3) Es necesario divulgar estos resultados y compartirlos con el mundo médico; 4) El proceso, así como está, es meramente un requisito universitario, pero no está beneficiando a la sociedad; y 5) Identificamos interés en participar en investigación de parte de algunos médicos especialistas.

A continuación, se presentó la pregunta: ¿Cuál será la estrategia para avanzar y desarrollar el proceso? La respuesta inmediata fue buscar el apoyo de la estructura organizativa de los Postgrados de Medicina y así involucrar a todos los Postgrados de medicina bajo el principio de que juntos lo haríamos mejor. Con este análisis, se presentó a la Coordinación de los Postgrados de Medicina, dirigida en ese entonces por el Dr. Carlos Vargas y a su equipo asesor del cual yo formaba parte en compañía del Dr. Tulio Nieto y Dr. Emilso Zelaya, el proyecto de realizar en forma regular, anualmente, el Congreso de los Postgrados de Medicina, el cual además de que sería un excelente medio de difusión, crearía una cultura de investigación en los alumnos, docentes y los futuros, y otro personal de salud que asista. Visualizamos además incentivar la competencia científica dentro de cada Postgrado y entre los Postgrados. Podríamos además involucrar a las más altas autoridades de salud y a las autoridades universitarias para que valoraran la importancia de incorporar la investigación como parte del aprendizaje y formación del residente. Además, se consideró que se podría incursionar en políticas de investigación en salud de interés nacional, entre otros. es decir, el limite sería el cielo.

Una vez aceptado el proyecto, incorporamos al mismo la idea de realizar el Primer Encuentro de Egresados, con la idea de que nuestros egresados volvieran al seno académico que los nutrió y formó. Esto lo hicimos con los siguientes propósitos: 1) Que los egresados hicieran una evaluación de la formación que habían recibido. Que identificaran las debilidades y forta- 
lezas una vez incorporados al ejercicio profesional y que esto nos sirviera como oportunidades de mejora; 2) Hacer una base de datos electrónica para mantener una comunicación efectiva y mantenerlos informados de nuestras actividades y enviarles documentación científica; y 3) Considerar de acuerdo a las debilidades identificadas, reforzamientos tutoriales.

\section{PRIMER CONGRESO DE LOS POSTGRADOS Y PRIMER ENCUENTRO DE EGRESADOS, 1994.}

El primer Congreso de los Postgrados y Primer Encuentro de Egresados se realizó en el año 1994. ¿Qué paso durante la implementación anual de los Congresos? Siguiendo el modelo de análisis propuesto por Avedis Donabedian (1966) de Estructura, Procesos y Resultados, identificamos grandes debilidades en la estructura como ser: 1) El proceso de Investigación no contaba con el apoyo de todos los jefes de programa, 2) Infraestructura hospitalaria no estaba de acuerdo con el desarrollo tecnológico, problemas de equipamiento y de servicios de apoyo diagnóstico, 3) Los actores del proceso (residentes y docentes) no tenían una formación adecuada en la metodología de la investigación, 4) La actividad de los residentes y médicos especialistas era principalmente asistencial, 5) No había reconocimiento al tiempo dedicado a la investigación, 6) No existía una ponderación óptima dentro de la evaluación del residente para la investigación y la misma no era homogénea en todos los Postgrados, 7) La investigación de calidad solo era realizada por una élite de profesionales, los que en su mayoría no son parte directa de los Postgrados, 8) No existía apoyo financiero regular para financiar investigación de alto nivel, 9) Los servicios de estadística no estaban automatizados, 10) Mal manejo del expediente clínico, 11) Algunas de las instituciones no tenían líneas de investigación bien definidas.

Entonces concluimos que estábamos ante un gran desafío, pero si no hubiéramos puesto en evidencia el problema a través del desarrollo de los congresos, no hubiéramos progresado hacia donde se está ahora. Y traigo a colación esta frase inspiradora de Paulo Coehlo "Nadie está a salvo de las derrotas, pero es mejor perder algunos combates en la lucha por nuestros sueños, que ser derrotados sin saber siquiera porque se está luchando". Identificando los problemas de estructura, se fueron elaborando los procesos de mejora para aquellos que eran competencia de la Coordinación de los Postgrados. Además, de manera estratégica se procedió a lo largo de nuestra participación como Coordinadora de Investigación de los Postgrados, a desarrollar los siguientes documentos, actividades y procesos. 1) Normas de investigación, en las cuales se indica los detalles normativos del proceso, incluye calendarización, como y quienes están involucrados, el rol de los asesores y revisores, así como penalizaciones; 2) Cursos de capacitación en metodología de la investigación para docentes con miras a la certificación como investigadores y que los capacitara para asesorías para ser revisores, esto se logro con el apoyo de la Unidad de Investigación Científica, Facultad de Ciencias Médicas, UNAH; Consejo Editorial Revista Médica Hondureña; Fundación Científica Pfizer; 3) Cursos de formación en metodología de la investigación para residentes, se ensayaron varios formas (dentro de la residencia, previo al ingreso y finalmente requisito de ingreso al momento de postularse); 4) Comité y reglamento de Ética; 5) Cursos sobre el Escrito Médico; 6) Guía para el docente de evaluación de los trabajos de investigación (lista de cotejo): a) Evaluar el protocolo (la lista de cotejo incluyó 25 items), b) Reportes semestrales 9 items, c) Reporte final del trabajo de investigación, d) Lista de cotejo para evaluar el escrito médico; 7) Instrucciones para los residentes de los postgrados de medicina UNAH, con relación a requisitos de publicación en la Revista Médica de los Postgrados; 8) Instrucciones para Ios autores; 9) Como elaborar referencias bibliográficas para una publicación científica; 10) Implementamos el proceso de evaluación de los mejores trabajos de investigación, el cual se fue modificando para convertir el proceso en algo más objetivo (el proceso inicialmente era in situ, modificándose posteriormente para que la evaluación pasara por dos comités uno interno y otro externo).

\section{RESULTADOS}

Los resultados de la implementación de estas actividades y procesos fueron los siguientes. 1) Sistematización de la investigación dentro del Proceso de enseñanza, 2) Se crearon dos espacios de divulgación científica: Congresos de los Postgrados y la Revista, 3) Algunos estudios de investigación realizados en grandes grupos de población permitieron la caracterización de una patología y por tanto su intervención, 4) Algunos trabajos por su calidad científica, fueron presentados en congresos a nivel internacional, 5) Algunos trabajos fueron publicados en Revistas internacionales, 6) Se participó en estudios multicéntricos, 7) Se identificó el comportamiento de alguna patología o situaciones de salud que difieren de lo reportado, 8) Se creó un espíritu de competencia constructiva dentro de cada Postgrado y entre los Postgrados, 9) Se establecieron las bases para garantizar la sostenibilidad del proceso de investigación y garantizar la realización de los Congresos de los Postgrados de Medicina y la Revista.

\section{REVISTA MÉDICA DE LOS POSTGRADOS DE MEDICINA}

La Revista Médica de los Postgrados de Medicina se consideró como el complemento ideal de los congresos para conocer lo nuestro. Como una herramienta fundamental para la divulgación de la investigación que se realiza en los Postgrados y para cumplir el objetivo de difundir los resultados de las investigaciones realizadas, en el año 1996, se creó la Revista Médica de los Postgrados por el mismo equipo de trabajo de la Coordinación de Docencia e Investigación de los Posgrados.

A propósito de su creación, el Dr. Emilso Zelaya quien fue el primer director de la Revista, en el Volumen 1 Número 1, expresa: "Grande ha sido la lucha para llegar a este momento, imponiéndose la gran inspiración y vocación hacia el trabajo de los principales gestores de la idea de fundar este órgano de divulgación científica que han sido los Drs. Martha Matamoros, Tulio Rigoberto Nieto, Carlos Vargas y Emilso Zelaya Lozano, 
quienes encontraron la solidaridad y apoyo de los Dres. Concepción Ferrufino, María Teresa de Grima y Jorge A. Sierra, responsables cada uno en su época de los destinos de los organismos universitarios que manejan el postgrado; en estas grandes tareas participan muchas personas que dan su relevante apoyo y esfuerzo, por ello es necesario mencionar por lo menos a los dirigentes ya que nuestro país debe fortalecer una política de estimulación a sus recursos humanos a fin de favorecer la emulación por parte de las nuevas generaciones". Y sigue indicando: "El complemento esencial de la investigación es la divulgación, con la finalidad en primer lugar de que los grupos médicos puedan conocer los resultados y saciar en ellos sus conocimientos y en segundo lugar para que tales resultados sirvan de mecanismo de retroalimentación al sistema de atención; las experiencias adquiridas y conocidas sirven para readecuar los planes y programas de trabajo, para remozar los sistemas normativos y para modernizar y poner al día las técnicas médicas. Con ese proceso, por añadidura se mejora la función docente, tanto en el pregrado como en el postgrado. La práctica de la investigación forma futuros profesionales e investigadores, "Es grande pues el acontecimiento de que nazca una publicación médica y que tenga sus bases fundamentales en el Postgrado de Medicina." Es así como 10 años después de esa publicación, cuando fungía como directora de la revista, escribimos un editorial en el volumen 10 numero 1, que en uno de los párrafos decía: "Con el apoyo de la Biblioteca Médica Nacional, Elaboramos un $C D$ que recopila todos nuestros números publicados durante diez años. A partir de diciembre 2006 estamos en internet en la página web de la Biblioteca Virtual en Salud. Esto sin lugar a dudas fue un paso significativo para los Postgrados de Medicina en general y para nuestra revista en particular". Además, comentamos: "Con nuestra edición en línea, el acceso a nuestras publicaciones traspasa los límites de los hospitales donde los postgrados se desarrollan y todo aquel que se interese en conocer toda la investigación que se genera en el seno de nuestros postgrados podrá acceder a esta valiosa información. Mejorar la visibilidad de nuestra revista, así como la calidad de nuestras publicaciones es el reto que nuestro comité editorial se ha impuesto, al formar parte de la prestigiosa Biblioteca Virtual en Salud; estamos seguros de que aumentará nuestro número de lectores." Seguimos indicando: "Los invitamos a que, superados los límites de llegar a cada uno de ustedes a través de nuestra edición impresa, con nuestra conquista del ciber espacio ya no tendrán excusa de conocer lo nuestro."

\section{COMO LO HICIMOS}

Podemos señalar que 1) El secreto del éxito no radica en fortalecer nuestras debilidades, sino en potenciar nuestras fortalezas. David Fischman; 2) Trabaja en equipo y multiplica los resultados. Nada de todo esto hubiese sido posible sin el apoyo y participación de un distinguido grupo de Especialistas, la mayoría sin tener una relación laborar con la Universidad, se involucraron directamente en el proceso de desarrollo en diferentes etapas del proceso. Destacamos lo siguiente: 1) Las autoridades, siendo receptivos a los cambios y a la innovación; 2) A los médicos especialistas, al participar como asesores y revisores de los trabajos de investigación, al participar en el comité de organización de los congresos, al ser miembros del comité editorial de la revista. Todos movidos por la idea de alcanzar el desarrollo cumpliendo con el compromiso de ser mejores cada día y ganarle la batalla al subdesarrollo y a la mediocridad, por el orgullo de ser hombres y mujeres profesionales de alto nivel y convertir a nuestros educandos en profesionales comprometidos con los mismos ideales; 3) Al personal administrativo, nuestras queridas secretarias que también se comprometieron arduamente con el proceso; 4) Y sobre todo los principales actores de este proceso, la más grande riqueza que tienen los Postgrados, Nuestros queridos Residentes, médicos jóvenes brillantes, que se han sometido a un proceso de selección muy exigente y que logran mantenerse dentro del sistema a pesar de sus largas y extenuantes horas de trabajo y que culminan sus estudios con la presentación de un trabajo de investigación.

\section{CONCLUSIÓN}

En resumen, podemos concluir que estas remembranzas del origen de los Congresos de los Postgrados de Medicina, solo nos traen grandes y buenos recuerdos. Conocer la historia es importante porque nos sirve para reafirmar nuestras raíces, para identificar las falencias y mejorar los procesos. ¿Que sigue o seguirá? ¿Cuál es el futuro? Lo que podemos compartir como reflexión en este momento es: "No esperes el momento perfecto toma el momento y hazlo perfecto."

\section{REFERENCIAS}

1. Consejo Editorial, Revista Médica Postgrados de Medicina. El porqué de una Revista Médica del Post-grado. Rev méd Postgrados Med, UNAH. 1996; 1 (1): 1.

2. Matamoros M. Nuestra edición en línea: una oportunidad de conocer lo nuestro. Rev méd Postgrados Med, UNAH. 2007;10 (1):1-2.
3. Matamoros M. Los Postgrados de medicina y su vinculación con la sociedad. Rev méd Postgrados Med, UNAH. 2007;10 (1): 89-90. 